\title{
PENGARUH BERAT BADAN TERHADAP GAYA GESEK DAN TIMBULNYA OSTEOARTHRITIS PADA ORANG DI ATAS 45 TAHUN DI RSUP PROF. DR. R. D. KANDOU MANADO
}

\author{
${ }^{1}$ Angela Sarah Sumual \\ ${ }^{2}$ Vennetia R Danes \\ ${ }^{2}$ Fransiska Lintong \\ ${ }^{1}$ Kandidat Skripsi Fakultas Kedokteran Universitas Sam Ratulangi Manado \\ ${ }^{2}$ Bagian Fisika Fakultas Kedokteran Universitas Sam Ratulangi Manado \\ Email: angelasarahsumual@yahoo.com
}

\begin{abstract}
The friction changes happened due to object weight increasement and friction coefficient. This research purpose is to see body weight influence at friction count, and if there is influence of body weight at friction count with osteoarthritis appearance in people above 45 years old at Prof. Dr. R. D. Kandou General Hospital. The research method that used is descriptive analytic with cross-sectional approach, samples were determined by consecutive sampling that is taken from patients above 45 years old. Data were obtained by measuring body weight and height scale 45 subjects who fulfilled inclusive criterias, then multiply friction coefficient of synovial joint 0,003 with body weight (Newton). Data were analyzed using SPSS 20.00 and Regresi Logistic test. Male (53,3\%) more often suffer Osteoarthritis than female (46,7\%), with IMT overweight (82,2\%) and friction 1,8 (22\%). Regresi Logistic test showed that there is a significant correlation between friction $(\mathrm{p}=0,026)$ and osteoarthritis appearance in people above 45 years old. But there was not significant correlation between age which affect friction $(\mathrm{p}=0,054)$ and appearance of osteoarthritis.Conclusion: There was significant correlation between body weight toward friction and osteoarthritis appearance in people above 45 years old.
\end{abstract}

Keywords: Body Weight, Friction, Osteoarthritis

\begin{abstract}
Abstrak: Perubahan gaya gesekan disebabkan kenaikan berat objek dan koefisien gesekan. Penelitian ini bertujuan membuktikan pengaruh berat badan terhadap gaya gesek, dan jika terdapat pengaruh dari berat badan terhadap gaya gesek dengan timbulnya osteoarthritis pada orang diatas 45 tahun di RSUP Prof. Dr. R. D. Kandou. Metode dalam penelitian ini yaitu deskriptif analitik dengan pendekatan cross sectional, sampel ditentukan secara konsekutive sampling, diambil dari pasien berumur diatas 45 tahun. Data diperoleh dengan melakukan pengukuran berat badan dan tinggi badan pada 45 subjek yang memenuhi kriteria inklusi, kemudian mengalikan koefisien gesekan sendi synovial 0,003 dengan berat badan (Newton). Data dianalisis menggunakan SPSS 20.00 dan uji Regresi Logistik. Pria (53,3\%) lebih sering menderita Osteoarthritis daripada wanita (46,7\%), IMT overweight $(82,2 \%)$ dan gaya gesekan 1,8 (22\%). Hasil uji regresi logistik menunjukan bahwa ada hubungan bermakna antara berat badan yang mempengaruhi gaya gesekan $(\mathrm{p}=0,026)$ dan timbulnya osteoarthritis pada orang diatas 45 tahun. Namun tidak didapatkan hubungan signifikan antara umur yang mempengaruhi gaya gesek $(\mathrm{p}=0,054)$ dan timbulnya osteoarthritis pada orang diatas 45 tahun. Simpulan: Ada hubungan bermakna antara berat badan terhadap gaya gesek dan timbulnya osteoarthritis pada orang diatas 45 tahun.
\end{abstract}

Kata kunci: Berat Badan, Gaya Gesek, Osteoarthritis 
Pembangunan kesehatan sebagai salah satu upaya pembangunan nasional diarahkan guna terciptanya kesadaran, kemauan dan kemampuan hidup sehat bagi setiap penduduk. Agar dapat mewujudkan derajat kesehatan yang optimal bagi masyarakat maka diselenggarakan upaya kesehatan berupa pendekatan pemeliharaan peningkatan kesehatan (promotif), pencegahan penyakit (preventif), penyembuhan penyakit (kuratif) dan pemulihan kesehatan (rehabilitatif) sebagaimana tercantum dalam UndangUndang Republik Indonesia Nomor 23 tahun 1992 tentang kesehatan (Departemen Kesehatan Republik Indonesia, 1992).

Osteoarthritis ditemukan oleh American College of Rheumatology sebagai sekelompok kondisi heterogen yang mengarah kepada tanda dan gejala sendi. Osteoarthritis merupakan penyakit degene-ratif dan progresif yang mengenai dua per tiga orang yang berumur lebih dari 65 tahun, dengan prevalensi $60,5 \%$ pada pria dan $70,5 \%$ pada wanita. Seiring bertambahnya jumlah kelahiran yang mencapai usia pertengahan dan obesitas serta peningkatannya dalam populasi masyarakat osteoarthritis akan berdampak lebih buruk di kemudian hari. Karena sifatnya yang kronik progresif, osteoarthritis berdampak sosio-ekonomik yang besar di negara maju dan di negara berkembang. ${ }^{1}$

Osteoarthritis adalah gangguan pada sendi yang bergerak. Penyakit ini ditandai oleh adanya abrasi rawan sendi dan adanya pembentukan tulang baru yang irreguler pada permukaan persendian. Nyeri menjadi gejala utama terbesar pada sendi yang mengalami osteoarthritis. Rasa nyeri diakibatkan setelah melakukan aktivitas dengan penggunaan sendi dan rasa nyeri dapat diringankan dengan istirahat. Trauma dan obesitas dapat meningkatkan resiko osteoarthritis. Namun baik penyebab maupun pengobatannya belum sepenuhnya diketahui. $^{1}$

Berdasarkan uraian di atas maka penulis merasa tertarik untuk melakukan penelitian dengan judul "Pengaruh Berat Badan terhadap Gaya Gesek dan Timbulnya Osteoarthritis pada Orang Di atas 45 tahun di RSUP Prof. Dr. R. D. Kandou Manado”.

\section{METODOLOGI}

Jenis penelitian ini menggunakan pendekatan studi potong melintang. Desain tersebut dipilih untuk mengetahui pengaruh gaya gesek terhadap osteoarthritis. Penelitian ini dilaksanakan pada bulan Agustus sampai Desember tahun 2012 yang bertempat di BLU RSUP Prof. Dr. R. D. Kandou Manado. Populasi yang diambil adalah semua orang yang berusia lanjut di RSUP Prof. Dr. R. D. Kandou Manado, dengan teknik pengambilan sampel yaitu secara konsekutif sampling dengan semua sampel yang datang dan memenuhi kriteria dijadikan sampel sampai jumlah sampel terpenuhi. Orang yang berusia lanjut yang terdiagnosa osteoartritis di RSUP Prof. Dr. R. D. Kandou Manado yang memenuhi kriteria klinis dan radiologis berjumlah 30 orang dan penderita yang berobat di RSUP Prof. Dr. R. D. Kandou Manado bulan (Agustus-Desember 2012) yang tidak terdiagnosa osteoarthritis berjumlah 15 orang, merupakan sampel yang diambil untuk digunakan dalam penelitian ini. Subjek penelitian adalah pasien yang terdiagnosa osteoarthritis, berusia 45 tahun atau lebih yang memenuhi kriteria klinis dan radiologis osteoarthritis. Pasien yang tidak diambil sebagai subjek penelitian adalah yang terdiagnosa penyakit penyerta sendi (Rheumatoid Arthritis dan Gout) dan post traumatik.

Osteoarthritis dijadikan sebagai variabel terikat sedangkan besarnya gaya gesek sebagai variabel bebas. Hipotesis yang diajukan yaitu, tidak adanya hubungan besar gaya gesekan terhadap osteoarthritis pada usia lanjut di RSUP Prof. Dr. R. D. Kandou Manado dan terdapatnya hubungan besar gaya gesek terhadap osteoarthritis pada usia lanjut di RSUP Prof. Dr. R. D. Kandou Manado. Definisi operasional dalam penelitian ini yaitu pasien yang terdiagnosa osteoarthritis sesuai hasil diagnosa dokter ahli dalam bagian tersebut dan peningkatan berat badan yang tidak sesuai 
dengan tinggi badan, dengan rumus perhitungan IMT, berat badan (kg) dibagi tinggi badan $(\mathrm{m})^{2}$. Pengkategorian hasil IMT dibagi menjadi empat kategori yaitu, underweight kecil dari 18.5, normal 18.524.9, overweight 25-29,9 dan obese 30.00 atau lebih. Definisi operasional yang digunakan juga meliputi maksimum kekuatan F (gaya gesekan) biasanya dijelaskan oleh $\mathrm{F}_{f}$, koefisien gesekan (M) dikalikan berat beban $(\mathrm{N})$, kita dapat menerapkan gaya gesekan sebesar $f$, koefisien gesekan persendian tulang $0,003(\mu)$ dikalikan berat badan $(\mathrm{N})^{2,3}$ Pengumpulan data primer diambil secara langsung dari responden dengan wawancara, mengobservasi langsung dan menimbang berat badan serta mengukur tinggi badan penderita, sedangkan data sekunder diperoleh dari data di RSUP Prof. Dr. R. D. Kandou Manado, yang berhubungan dengan penelitian mengenai data pendahuluan yang berhubungan dengan kasus Osteoartritis yang ada. Dalam penelitian ini instrumen penelitian yang digunakan adalah, timbangan berat badan, pengukur tinggi badan, data pasien osteoarthritis di RSUP Prof. Dr. R. D. Kandou Manado, lembar persetujuan dan lembar observasi.

Data diolah dengan menggunakan program Statistical Product and Service Solution (SPSS) versi.20.00. Data yang diperoleh akan dianalisa dan diinterpretasikan dengan tahapan awal analisis univariat dengan mengolah data dan dianalisa secara deskriptif dengan menggunakan tabel distribusi frekwensi dan analisis persentase, kemudian analisis multivariat digunakan untuk mengetahui pengaruh variabel bebas yaitu besar gaya gesekan dan umur terhadap variabel terikat yaitu osteoarthritis dengan uji statistik yang akan digunakan adalah dengan uji regresi logistik. Uji regresi logistik ini digunakan pada variabel bebas berskala numerik, sedangkan variabel tergantungnya berskala nominal dikotom, sesuai kebutuhan penelitian ini.

\section{HASIL PENELITIAN}

Distribusi data berdasarkan karakteris- tik osteoarthritis, terdiri dari karakteristik subjek penelitian dan karakteristik faktor resiko. Dari data primer yang telah dikumpulkan selama penelitian, ditabulasikan dengan hasil sebagai berikut:

\section{Karakteristik Subjek Penelitian}

Karakteristik subjek penelitian dalam penelitian ini meliputi umur dan jenis kelamin. Dengan hasil sebagai berikut:

\section{Umur}

Distribusi data berdasarkan umur penderita dikelompokkan menjadi empat kelompok, yaitu umur 45-59 tahun, 60-74 tahun, 75-90 tahun dan lebih dari 90 tahun. Diperoleh data pada kelompok umur 45-59 tahun sebanyak tujuh orang (15,6\%), diikuti kelompok umur 60-74 tahun sebanyak 30 orang $(66,7 \%)$, kelompok umur 75-90 tahun sebanyak delapan orang $(17,8 \%)$, dan yang paling sedikit atau tidak ditemukan pada kelompok umur lebih dari 90 tahun (0\%). Distribusi jumlah data menurut umur pada penderita dapat dilihat pada tabel 1 .

Tabel 1. Distribusi data berdasarkan umur pada penderita Osteoarthritis di RSUP Prof. Dr. R.D. Kandou Manado

\begin{tabular}{ccc}
\hline $\begin{array}{c}\text { Kelompok } \\
\text { Umur }\end{array}$ & $\begin{array}{c}\text { Jumlah } \\
\text { (n) }\end{array}$ & $\begin{array}{c}\text { Persentase } \\
(\%)\end{array}$ \\
\hline $45-59$ tahun & 7 & $15,6 \%$ \\
$60-74$ tahun & 30 & $66,7 \%$ \\
$75-90$ tahun & 8 & $17,8 \%$ \\
$>90$ tahun & 0 & $0 \%$ \\
Total & 45 & $100 \%$ \\
\hline
\end{tabular}

\section{Jenis Kelamin}

Distribusi data berdasarkan jenis kelamin penderita dikategorikan menjadi dua kategori yaitu pria dan wanita. Data yang diperoleh berdasarkan tabulasi data diperoleh yaitu sebanyak 24 orang (53,3\%) pada pria dan 21 orang $(46,7 \%)$ pada wanita. Distribusi data berdasarkan jenis kelamin dapat dilihat pada tabel 2 . 
Tabel 2. Distribusi data menurut jenis kelamin penderita Osteoarthritis di RSUP Prof. Dr. R. D. Kandou Manado

\begin{tabular}{ccc}
\hline Jenis Kelamin & $\begin{array}{c}\text { Jumlah } \\
\text { (n) }\end{array}$ & $\begin{array}{c}\text { Persentase } \\
\text { (\%) }\end{array}$ \\
\hline Pria & 24 & $53,3 \%$ \\
Wanita & 21 & $46,7 \%$ \\
Total & 45 & $100 \%$ \\
\hline
\end{tabular}

\section{Karakteristik Faktor Resiko}

Karakteristik faktor resiko pada penelitian ini yaitu berat badan dengan mengkategorikan ke dalam Indeks Masa Tubuh (IMT), penggunaan sendiri berlebihan dan lamanya penderita menderita Osteoarthritis, dengan hasil sebagai berikut:

\section{Berat Badan}

Distribusi data berdasarkan berat badan berlebihan yang telah dihitung berdasarkan kategori Indeks Massa Tubuh (IMT) dikategorikan menjadi empat kelompok yaitu underweight, normal, overweight dan obese. Data yang diperoleh yaitu pada penderita dengan IMT underweight berjumlah satu orang (2,2\%), normal berjumlah tiga orang $(6,7 \%)$, overweight berjumlah 37 orang $(82,2 \%)$, dan obese berjumlah empat orang $(8,9 \%)$. Distribusi data menurut kategori IMT dapat dilihat pada tabel 3.

\section{Penggunaan Sendi}

Distribusi data berdasarkan penggunaan sendi berlebihan dikategorikan menjadi tiga bagian yaitu ringan yang termasuk di dalamnya kegitan sehari-hari, sedang dengan melakukan pengangkatan beban berlebihan dan olahraga lari, dan berat yaitu pengangkatan beban berlebihan dalam waktu lama secara terus menerus. Data yang diperoleh yaitu sebanyak 37 orang $(82,2 \%)$ dengan intensitas ringan, sebanyak tujuh orang (15,6\%) dengan intensitas sedang dan sebanyak satu orang $(2,2 \%)$ pada intensitas berat. Distribusi data berdasarkan penggunaan sendi berlebihan dapat dilihat pada tabel 4 .
Tabel 3. Distribusi data menurut kategori IMT penderita Osteoarthritis di RSUP Prof. Dr. R. D. Kandou Manado

\begin{tabular}{ccc}
\hline IMT & $\begin{array}{c}\text { Jumlah } \\
\text { (n) }\end{array}$ & $\begin{array}{c}\text { Persentase } \\
(\mathbf{\% )}\end{array}$ \\
\hline Underweight & 1 & $2,2 \%$ \\
Normal & 3 & $6,7 \%$ \\
Overweight & 37 & $82,2 \%$ \\
Obese & 4 & $8,9 \%$ \\
Total & 45 & $100 \%$ \\
\hline
\end{tabular}

Tabel 4. Distribusi data menurut penggunaan sendi pada penderita Osteoarthritis di RSUP Prof. Dr. R. D. Kandou Manado

\begin{tabular}{ccc}
\hline $\begin{array}{c}\text { Penggunaan } \\
\text { Sendi }\end{array}$ & Jumlah (n) & $\begin{array}{c}\text { Persentase } \\
\text { (\%) }\end{array}$ \\
\hline Ringan & 37 & $82,2 \%$ \\
Sedang & 7 & $15,6 \%$ \\
Berat & 1 & $2,2 \%$ \\
Total & 45 & $100 \%$ \\
\hline
\end{tabular}

\section{Lamanya Gejala}

Distribusi lamanya gejala yang telah dialami pasien dikategorikan menjadi tiga kelompok. Data yang diperoleh yaitu kurang dari satu tahun berjumlah 25 orang (55,6\%), 1-3 tahun berjumlah 14 orang $(31,1 \%)$, dan lebih dari tiga tahun berjumlah enam orang (13,3\%). Distribusi data berdasarkan lamanya gejala pada penderita osteoarthritis dapat dilihat pada tabel 5.

Tabel 5. Distribusi Lamanya Gejala penderita Osteoarthritis di RSUP Prof. Dr. R. D. Kandou Manado

\begin{tabular}{lcc}
\hline Lamanya Gejala & $\begin{array}{c}\text { Jumlah } \\
\text { (n) }\end{array}$ & $\begin{array}{c}\text { Persentase } \\
\text { (\%) }\end{array}$ \\
\hline$<1$ tahun & 25 & $55,6 \%$ \\
$1-3$ tahun & 14 & $31,1 \%$ \\
$>3$ tahun & 6 & $13,3 \%$ \\
$\quad$ Total & 45 & $100 \%$ \\
\hline Distribusi Data & Berdasarkan Gaya \\
Gesek & \multicolumn{2}{c}{}
\end{tabular}

Berdasarkan besarnya gaya gesek yang diperoleh dari berat badan dalam satuan Newton kemudian dikalikan dengan koefisien gesekan kinetik persendian 
synovial tulang sebesar 0,003 maka, data primer yang telah dikumpulkan selama penelitian ditabulasikan dengan hasil yang dapat dilihat pada tabel 6 .

Tabel 6. Distribusi data berdasarkan besarnya gaya gesek pada pasien di RSUP Prof. Dr. R. D. Kandou Manado

\begin{tabular}{ccc}
\hline $\begin{array}{c}\text { Besar Gaya } \\
\text { Gesek }\end{array}$ & $\begin{array}{c}\text { Jumlah } \\
\text { (n) }\end{array}$ & $\begin{array}{c}\text { Persentase } \\
\text { (\%) }\end{array}$ \\
\hline 1,2 & 3 & 6,6 \\
1,3 & 2 & 4,4 \\
1,4 & 2 & 4,4 \\
1,5 & 1 & 2,2 \\
1,6 & 4 & 8,8 \\
1,7 & 2 & 4,4 \\
1,8 & 10 & 22 \\
1,9 & 7 & 15,4 \\
2,0 & 5 & 11 \\
2,1 & 6 & 13,2 \\
2,2 & 1 & 2,2 \\
2,3 & 1 & 2,2 \\
2,5 & 1 & 2,2 \\
Total & 45 & $100 \%$ \\
\hline
\end{tabular}

Tabel 7. Hasil analisis Multivariat Uji Regresi Logistik

\begin{tabular}{ccc}
\hline & $\begin{array}{c}\text { Nilai } \boldsymbol{p} \\
\text { value }\end{array}$ & $\begin{array}{c}\text { Hasil } \\
\text { Analisis }\end{array}$ \\
\hline Gaya Gesek (f) & 0,026 & Signifikan \\
Umur & 0,054 & $\begin{array}{c}\text { Tidak } \\
\text { Signifikan }\end{array}$ \\
\hline
\end{tabular}

\section{Hasil Analisis Data}

Analisis multivariat dilakukan untuk dapat mengetahui hubungan antara besarnya gaya gesekan dan umur terhadap osteoarthritis. Analisis dilakukan dengan menggunakan analisis regresi logistik. Hasil dari analisis uji ini didapatkan bahwa gaya gesek dengan nilai $p=0,026$ dan umur dengan nilai $p=0,054$.

\section{BAHASAN}

Pembahasan dalam penelitian ini meliputi pembahasan distribusi frekwensi data karakteristik subjek penelitian, karakteristik faktor resiko dan hasil analisis multivariat.

\section{Karakteristik Subjek Penelitian}

Setelah dilakukan pengolahan data diperoleh data menurut usia pada kelompok umur 60-74 tahun sebanyak 30 orang (66,7\%), diikuti kelompok umur 75-90 tahun sebanyak delapan orang (17,8\%), kelompok umur 45-59 tahun sebanyak tujuh orang $(15,6 \%)$ dan yang paling sedikit tidak ditemukan pada kelompok umur lebih dari 90 tahun (0\%) dengan usia terendah 51 tahun dan usia tertinggi 82 tahun. Pengelompokan usia dilakukan berdasarkan pengkategorian usia lanjut menurut WHO. ${ }^{4}$ Prevalensi osteoarthritis di Indonesia cukup tinggi yaitu 5\% pada usia kurang dari 40 tahun, 30\% pada usia 40-60 tahun dan $65 \%$ pada usia lebih dari 61 tahun. $^{5}$

Distribusi data selanjutnya diperoleh berdasarkan jenis kelamin penderita dikategorikan menjadi dua kategori yaitu pria dan wanita. Data yang diperoleh berdasarkan tabulasi data diperoleh yaitu sebanyak 24 orang $(53,3 \%)$ pada pria dan 21 orang $(46,7 \%)$ pada wanita. Pria ditemukan lebih banyak dibandingkan wanita pada osteoarthritis. Namun menurut penelitian lain ditemukan bahwa setelah usia 50 tahun, wanita lebih sering menderita osteoarthritis dibandingkan pria, dengan gejala pertama kali timbul pada umur 40 tahun dan perkembangannya perlahan. ${ }^{6}$ Wanita ditemukan memiliki progresitivitas lebih cepat dan membutuhkan intervensi pembedahan lebih tinggi daripada pria. ${ }^{7}$

\section{Karakteristik Faktor Resiko}

Distribusi data berdasarkan faktor resiko yang diteliti yaitu berat badan yang telah dihitung berdasarkan perhitungan Indeks Massa Tubuh (IMT) dikategorikan menjadi empat kelompok yaitu underweight, normal, overweight dan obese. Data yang diperoleh yaitu terbanyak pada penderita dengan IMT overweight berjumlah 37 orang (82,2\%), kemudian obese 
berjumlah empat orang (8,9\%), normal sebanyak tiga orang $(6,7 \%)$ dan underweight sebanyak satu orang (2,2\%). Bobot tubuh rata-rata yaitu $61,20 \mathrm{~kg}$ yang dalam Newton, 600 N. Berdasarkan perhitungan hasil Indeks Masa Tubuh (IMT) rata-rata pasien yaitu 25,24 termasuk dalam kategori overweight. Kegemukan telah lama ditemukan sebagai faktor resiko yang terpenting dari penyebab dan progresi dari OA lutut. Kegemukan mengarah ke OA tidak hanya karena penyebab mekanik tetapi juga efek metabolik. ${ }^{8}$

Kemudian distribusi data berdasarkan penggunaan sendi dikategorikan menjadi tiga bagian yaitu ringan yang termasuk di dalamnya kegitan sehari-hari, sedang dengan melakukan pengangkatan beban berlebihan dan olahraga lari, dan berat yaitu pengangkatan beban berlebihan dalam waktu lama secara terus menerus. Data yang diperoleh yaitu sebanyak 37 orang $(82,2 \%)$ dengan intensitas ringan, sebanyak tujuh orang (15,6\%) dengan intensitas sedang dan sebanyak satu orang $(2,2 \%)$ pada intensitas berat. Pada tahap awal penyakit ini, penderita mengalami rasa nyeri setelah menggunakan sendi, dan rasa nyeri itu dapat bertambah parah sepanjang hari. ${ }^{1}$ Berdasarkan lamanya gejala yang telah dialami pasien dikategorikan menjadi tiga kelompok. Data yang diperoleh yaitu kurang dari satu tahun berjumlah 25 orang (55,6\%), 1-3 tahun berjumlah 14 orang $(31,1 \%)$, dan lebih dari tahun berjumlah enam orang (13,3\%). Berdasarkan penelitian lainnya ditemukan bahwa gejala pertama kali timbul pada umur 40 tahun dan perkembangannya perlahan. ${ }^{6}$

\section{Besar Gaya Gesekan pada Penderita Osteoarthritis}

Berdasarkan hasil penelitian dengan melakukan penimbangan berat badan dan pengukuran tinggi badan pada pasien di RSUP Prof. Dr. R. D. Kandou Manado, didapatkan pasien dengan diagnosa osteoarthritis sebanyak 30 orang (66,7\%) dan pasien dengan diagnosa non-osteoarthritis berjumlah 15 orang (33,3\%), dengan total subjek penelitian 45 orang (100\%). Juga ditemukan bahwa besar gaya gesekan ratarata pada penderita adalah 1,801 dengan hasil terendah 1,2 dan hasil tertinggi sebesar 2,5. Hal ini menjelaskan bahwa besar gaya gesekan yang dimiliki setiap individu berbeda-beda satu dengan yang lainnya.

Pasien dengan beban tubuh besar maka akan besar pula gaya gesekan yang terjadi antar sendinya dan akan menimbulkan nyeri pada penderita osteoarthritis. Pengurangan berat badan setengah kilogram menghemat beban lutut $2 \mathrm{~kg}$, dan berkurangnya berat badan $2 \mathrm{~kg}$ menurunkan resiko OA sendi lutut 50\% pada wanita. ${ }^{6,9}$ Pernyataan bahwa makin kasar permukaan benda yang saling bersinggungan maka makin besar gaya gesekan juga berlaku dengan penjelasan bahwa penipisan tulang kartilago dan pembentukan osteofit pada pinggir-pinggir tulang menyebabkan permukaan tulang menjadi kasar sehingga dengan bersinggungannya antar tulang menyebabkan nyeri yang hebat dan pembatasan dalam pergerakkan. Mengontrol besar gaya gesekan dilakukan dengan mengontrol nilai koefisien gesekannya. ${ }^{1,10}$ Koefisien gesekan dapat diperkecil dengan memperhalus permukaan yang melakukan kontak, contohnya cairan synovial pada sendi yang melumasi persendian tulang. ${ }^{11}$

Hasil analisis pengaruh berat badan terhadap gaya gesek menunjukkan bahwa makin tinggi berat badan maka akan makin tinggi juga besar gaya gesek yang didapatkan, sehingga tiap individu memiliki besar gaya gesekan yang berbeda-beda. Hasil lain yang didapatkan yaitu bahwa pada penelitian ini terdapat hubungan gaya gesek pada sendi terhadap osteoartritis dengan analisis regresi logistik diperoleh hasil yang sebagaimana dapat dilihat pada tabel 7 , sehingga dapat disimpulkan bahwa makin tinggi gaya gesek pada persendian tulang, maka makin tinggi peluang terjadinya osteoarthritis. Dengan menjaga berat badan agar proporsional dengan rutin berolahraga dan diet yang seimbang serta tidak mengangkat beban berat dalam waktu lama secara terus menerus, dapat mencegah terjadinya osteoarthritis. ${ }^{6}$ 


\section{SIMPULAN}

Pada penelitian ini hasil simpulan yang didapatkan yaitu adanya pengaruh berat badan penderita terhadap besarnya gaya gesek dan terdapat pula hubungan antara gaya gesek dengan osteoarthritis pada orang diatas 45 tahun di RSUP Prof. Dr. R. D. Kandou Manado.

\section{UCAPAN TERIMA KASIH}

Ucapan terima kasih disampaikan kepada Drs. Bahrun M.Si selaku penguji I, dr. Jimmy Rumampuk M.Kes AIFO selaku penguji II, dan kepada semua pihak yang baik secara langsung maupun tidak langsung telah menumbuhkan ide atau gagasan dalam pemikiran penulis sehingga dapat menyelesaikan artikel ini.

\section{DAFTAR PUSTAKA}

1. Helmtrud I, Roach, Simon T. Bone and Osteoarthritis. London: Springer, 2007; p.1-3.

2. Cameron J, Skofronick J, Grant R. Physics of the Body (Second Edition). Medical Physics Publishing, 1999; p.39-41. Available at: http://medicalphysics.org/../ WebPOTB.pdf

3. Serway, Raymond, Faughn J. College Physics (Sixth Edition). Canada: Brooks/ Cole-Thomson Learning, 2003; p.101. Available at: http:// hypertextbook.com/../ ConnieQiu.shtml
4. Muriel Skeet. Protecting the Health of the Elderly. A Review of WHO activities. Europe: Denmark, 1983; p.3.

5. Resty Dwi Handayani. Faktor Resiko yang Mempengaruhi Terjadinya Osteoarthritis pada Lansia di Instalasi Rehabilitasi Medik RSU Haji Surabaya Tahun 2008. Surabaya: FKM UNAIR, 2008. Diunduh dari: URL: http://adln. fkm.unair.ac.id/gdl.php\%3Fmod\%brow se\&op\%read\&id\%adlnfkm-adln-s22009-restydwiha-1110

6. Soenarwo HBM. Osteoarthritis. Jakarta: Halimun Medical Centre dan AlMawardi Prima, 2011; p.7-15.

7. Rosemann T, Laux G, Szecsenyi J. Osteoarthritis: Quality of life, comorbidities, medication and health service utilizationassesed in a large sample of primary care patients. Journal of Orthopedic Surgery \& Research. 2007; 2: 12.

8. Yusuf E. Metabolic Factors in Osteoarthritis: Obese People Do Not Walk on Their Hands. Arthritis Research \& Therapy. 2012; 14: 123.

9. Messier SP, Gutekunst DJ, Davis C, DeVita P. Weight loss reduces kneejoint loads in overweight and obese older adults with knee osteoarthritis. Arthritis \& Rheumatism. 2005; 52(7): 2026-2032.

10. Knudson Duane. Fundamentals of Biomechanics. California State University: Springer, 2007; p.146.

11. Popov Valentine. Contact Mechanics and Friction. Berline University of Technology: Springer, 2010; p.134140. 